\title{
РОЛЬ ИНФОРМАЦИОННОГО ФОНА В ДИНАМИКЕ КАПИТАЛИЗАЦИИ ТЕХНОЛОГИЧЕСКИХ КОМПАНИЙ
}

\author{
(c) 2021 Родионов Дмитрий Григорьевич \\ Доктор экономических наук, профессор \\ Высшая инженерно-экономическая школа \\ Санкт-Петербургский политехнический университет Петра Великого, Россия, Санкт-Петербург \\ E-mail: dmitry.rodionov@spbstu.ru
}

(c) 2021 Тенишев Тимур Владиславович

студент

Высшая инженерно-экономическая школа

Санкт-Петербургский политехнический университет Петра Великого, Россия, Санкт-Петербург

E-mail: tenishev.tv@edu.spbstu.ru

(c) 2021 Конников Евгений Александрович

кандидат экономических наук, доцент

Высшая инженерно-экономическая школа

Санкт-Петербургский политехнический университет Петра Великого, Россия, Санкт-Петербург

E-mail: konnikov.evgeniy@gmail.com

В статье рассматриваются особенности функционирования технологических компаний и механизмы обмена информацией между технологическими предприятиями и их основными стейкхолдерами. Приводится сравнение между традиционными средствами массовой информации и социальными сетями как основными посредниками в обмене информации, анализируется их роль в динамике капитализации технологических компаний.

Ключевые слова: технологический сектор, рыночная капитализация, социальные сети, СМИ, репутация, новости, информация.

На данный момент весь мир переходит к новому укладу экономики, где основополагающую роль играют информационные технологии. Уже сейчас в ряде развитых и развивающихся стран ИТ-сектор является одним из самых быстрорастущих. Например, в России данный сектор по результатам 2020 года оказался в пятерке по скорости развития, уступив только химической, мебельной и фармацевтической промышленности, а также финансовому сектору [1]. Помимо высокой скорости роста, в ряде стран сектор информационных технологий также обладает достаточно весомой долей в ВВП [20]. Как отражено на рисунке 1, в странах Европы он составляет от

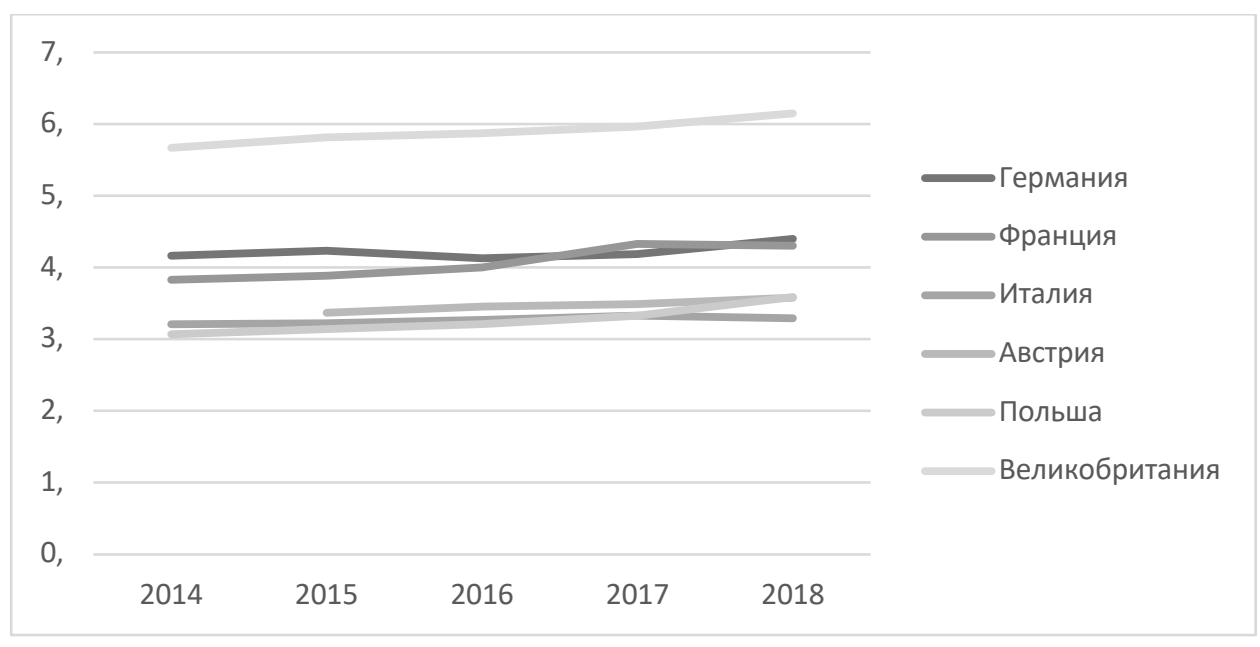

Рис. 1. Вклад ИТ-сектора в ВВП по странам. 
Таблица 1. Капитализация технологических компаний по годам, млрд. долл.

\begin{tabular}{|l|l|l|l|l|l|l|l|}
\hline \multicolumn{1}{|c|}{2005} & & \multicolumn{1}{c|}{2010} & & \multicolumn{1}{c|}{2015} & & \multicolumn{1}{c|}{2020} & \\
\hline Microsoft & 272 & Apple & 297 & Apple & 584 & Apple & 2225 \\
\hline Intel & 148 & Microsoft & 235 & $\begin{array}{l}\text { Alphabet } \\
\text { (Google) }\end{array}$ & 528 & Microsoft & 1681 \\
\hline IBM & 129 & Google & - & Microsoft & 440 & Amazon & 1634 \\
\hline Google & - & IBM & 180 & Amazon & 318 & $\begin{array}{l}\text { Alphabet } \\
\text { (Google) }\end{array}$ & 1185 \\
\hline Cisco & 105 & Oracle & 158 & Facebook & 297 & Facebook & 778 \\
\hline
\end{tabular}

3\% до 6\% процентов от общего ВВП.

Еще более стремительный рост сектора информационных технологий можно увидеть, если посмотреть на стоимость акций технологических компаний или соответствующих им ETF-фондов. Так, например, стоимость акций ETF-фонда «FXIT» почти за восемь лет выросла на 986\%, что существенно опережает динамику аналогичных ETF-фондов по иным отраслям [10].

Помимо того, что технологический сектор растет достаточно стремительно, компании быстро теряют лидерство в нем. Например, лишь две компании из списка пяти крупнейших по рыночной капитализации в 2005 году смогли остаться в этом списке к 2020 году - что отображено в таблице 1 [5].

Из таблицы видно, что за период с 2015 по 2020 годы рост капитализации технологических компаний только ускорился, что повышает риски потери лидерства для отдельных из них. Это показывает, что данный рынок является особо конкурентным, и любая ошибка в управлении предприятием может обернуться потерей ли- дерства на рынке. Новые игроки появляются на рынке и растут довольно быстро, в то время как старые нередко оказываются оттеснены. В данной ситуации управлять капитализацией компании необходимо особенно эффективно, что наталкивает на необходимость исследования факторов, влияющих на капитализацию компании в IT-секторе, и способов управления ими.

Среди факторов, влияющих на капитализацию технологических компаний, особенно выделяется освещение их деятельности в социальных сетях и средствах массовой информации. Так, широко освещенный в прессе скандал с передачей данных компании Cambridge Analytica весной 2018 года стоил компании Facebook потери в капитализации в размере больше 100 миллиардов долларов [18]. Таким образом, управление информационным фоном является одним из наиболее актуальных методов повышения рыночной капитализации компании на данный момент.

Однако перед анализом информационного фона технологических компаний стоит рассмо-

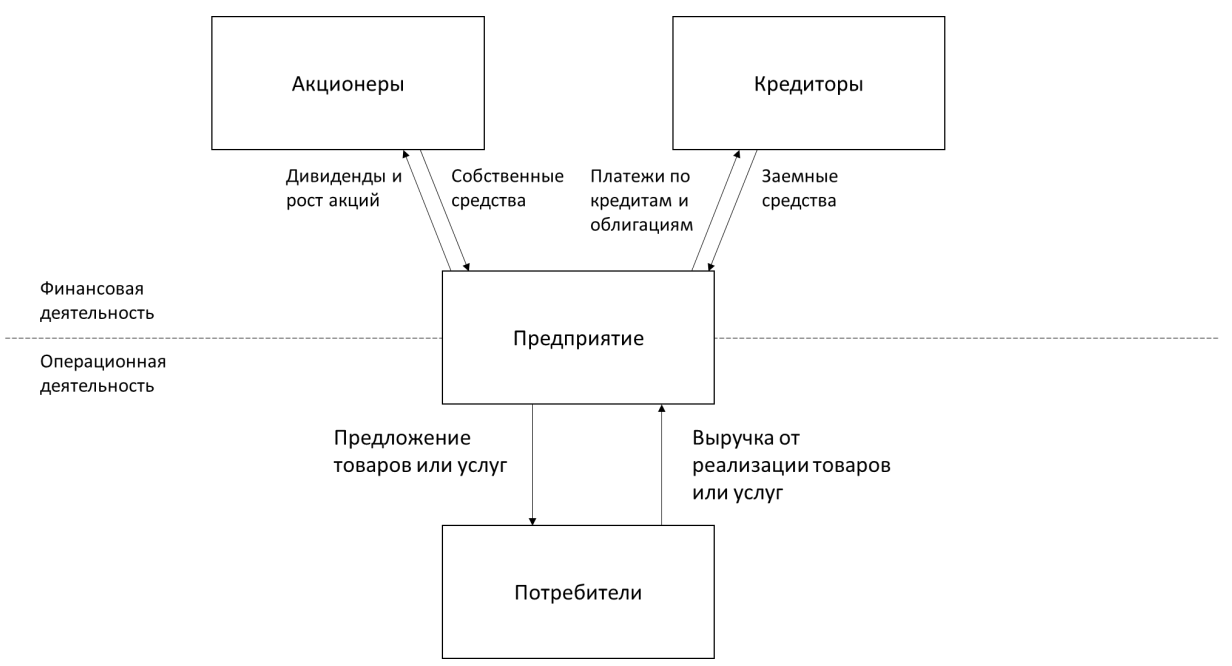

Puc. 2. Движение материальных и денежных потоков между предприятием, его клиентами и инвесторами. 
треть особенности их деятельности и управления различными ресурсами, влияющими на их финансовые показатели. В первую очередь на результативность технологических компаний влияет эффективность их взаимодействия с клиентами, которые приобретают услуги и формируют выручку компании, и с инвесторами, которые готовы вкладывать финансовые средства в собственный и заемный капитал предприятия в обмен на ожидаемую или обещанную доходность или прирост стоимости их доли в собственном капитале. Схема данного взаимодействия компании с потребителями и инвесторами отражена на рисунке 2.

Также на результативность технологических компаний влияет использование имеющихся ресурсов для создания ценности потребителю. Л.Вартьяк в своем исследовании исследует различные методы классификации ресурсов, которыми могут пользоваться компании [27]. Наиболее детальным из предложенных им методов анализа внутренних ресурсов компании является модель McKinsey 7S, которая включает в себя следующие факторы: стратегия, структура, системы, стиль, сотрудники, ценности и навыки.

М.Б. Гаспар, С. Г. Попеску, М. Драгомир и другие применяют данный метод для компании, занимающейся производством программного обеспечения, и выделяют важность управления человеческими ресурсами, поскольку эффективность сотрудников является одним из ключевых факторов эффективности технологических компаний [7]. При этом на данный момент высокотехнологичные компании сталкиваются с острой нехваткой высококвалифицированных сотрудников, что приводит к возрастанию затрат на поиск персонала и построение бренда работодателя. И. Машайя заявляет, что управление человеческими ресурсами особенно важно для технологических компаний из-за высоких темпов роста и быстрой экспансии на глобальных рынках. Необходимо не только привлекать новых сотрудников, но и поддерживать положительные впечатления от работы у уже давно работающих [17].

Помимо этого, согласно исследованию А.Х.Р. Хенсена и Дж.К.Донга, проведение исследований и разработок внутри крупных компаний также является важным фактором, поскольку они оказываются более инновационными и регистрируют больше патентов [13]. Роль исследований и разработок также подтверждается ста- тьей Ч.Жу, Ю.Ванга и Ц.Ванга, где заявляется, что исследования и разработки положительно сказываются на результативности технологических компаний, при этом поддержка со стороны государства повышает вероятность успешного результата НИОКР [32].

Т.А.Сид, К.Блом и Т.Пападопулос приходят к выводу, что важно не только привлекать ресурсы, но и развивать компетенции, позволяющие грамотно их использовать. Важную роль, согласно их исследованию, в формировании этих способностей играет среда предприятия, которая у технологических компаний обладает высокой степенью неопределенности. Помимо этого, авторы заключают, что развитие способностей для использования ресурсов более важно для малых и средних предприятий, которые не имеют рычага, позволяющего с этими способностями экспериментировать, и при этом сталкиваются с гораздо большей неопределенностью внешней среды. Авторы приходят к выводу, что высокая изменчивость внешней среды предприятия положительно влияет на их деятельность, и что необходимо развиваться не на одной технологии, а формировать целую совокупность из разных технологий [24].

С.Петтер, В.ДеЛон и Э.Р.МакЛин создают свою модель факторов, влияющих на деятельность технологических компаний, в которую включают:

1. качество предлагаемых компанией систем - то есть желательные характеристики этих систем;

2. качество информации - желательные характеристики выходных данных из информационных систем;

3. качество предоставления услуг - то есть качество обслуживания клиентов или оказания им технической поддержки [22].

Эти факторы, согласно модели успеха ДеЛона и МакЛина, оказывают влияние на использование клиентами предлагаемой предприятием системы и степень их довольства, что в итоге и определяет успешность или неуспешность предлагаемых технологическим предприятием продуктов.

Ч.Баден-Фюллер и С.Хэфлигер заявляют, что инновационные бизнес-модели возникать как на основе старого продукта (например, как изобретение электрических двигателей меняло производство, изначально построенное на паровых двигателях), так и предлагать что-то но- 
вое. Выбор бизнес-модели влияет на то, как коммерциализируется технология и какую выгоду извлекает от этого предприятие. Бизнес-модель при этом должна быть достаточно гибкой, чтобы ее можно было адаптировать под изменчивые на технологичных рынках потребности клиентов [3].

Исследование М.Г. Мартинез, Ф. Зуагхи, Т.Г.Марко и К.Робинсон, в отличие от других, рассматривает, как неэффективное привлечение и использование ресурсов негативно влияет на деятельность технологических компаний [30]. Авторы исследования приходят к выводу, что компании с большим финансированием исследований и разработок имеют меньшую вероятность обанкротиться, что согласуется с исследованиями [13] и [32]. Основными факторами провала технологических компаний в данном исследовании являются плохая политика НИОКР (главным образом определяется интенсивностью исследований и человеческими ресурсами), неэффективное взаимодействие с субъектами внешней среды и медленная адаптация под меняющуюся макроэкономическую обстановку. Человеческие ресурсы, согласно заявлению авторов, особенно важны, поскольку именно они позволяют развивать необходимые компетенции и быстро адаптироваться к меняющейся внешней среде.

К.С.Кравенс и Э.Г.Оливер также подкрепляют важность человеческих ресурсов для IT-компаний, поскольку они больше всего влияют на репутацию предприятия, которая в свою очередь является конкурентным преимуществом компании [6]. Помимо трудовых факторов, на репутацию также влияет качество используемых внутри самой компании информационных систем, согласно исследованию К. Перез-Корнеджо, Э. де Куэведо-Пуэнте и Х.Б.Дельградо-Гарсии [21]. А. Вех, М. Гёбель и Р.Вогель провели библиометрический анализ исследований репутации и пришли к выводу, что репутация анализируется в основном в аспектах экономики, маркетинга и менеджмента, при этом в исследованиях репутации они находят ряд концептуальных несоответствий и советуют рассматривать ее в контексте отношений между рыночными субъектами [28].

Словарь Merriam-Webster дает три варианта определения термина «репутация»:

1. общее качество или характеристика объекта, как ее видят или воспринимают люди в целом;
2. признание другими людьми каких-либо характеристик или особенностей объекта;

3. наличие уважения к объекту со стороны общественности или отдельных лиц: хорошее имя [23].

Н.Гатцерт подразделяет репутацию предприятия на финансовые и нефинансовые аспекты. Нефинансовые аспекты репутации больше важны сотрудникам и потребителям, в то время как инвесторы заинтересованы в финансовых аспектах. Они по-разному влияют на финансовый результат компании - так, нефинансовые аспекты репутации имеют скорее долгосрочный эффект на финансовые показатели деятельности предприятия и поэтому нуждаются в более тщательной оценке со стороны руководства. Гатцерт также находит, что новости, связанные с мошенничеством и иными преступлениями, вызывают наибольшие финансовые потери для компании [11].

Одной из ранних попыток количественно измерить репутацию было исследование Ч. С. Чой, Ю.М. Квака и Ч. Чоэ, где они предложили два индекса корпоративной социальной ответственности и, применив их, нашли положительную связь между средневзвешенным по стейкхолдерам индексом корпоративной социальной ответственности и показателями рентабельности предприятия [4]. С этими выводами согласуется исследование С.Мишры и Д.Суара, в ходе которого они находят связь между корпоративной социальной ответственностью и финансовыми результатами деятельности публичных компаний и приходят к выводу, что корпоративная социальная ответственность может нести выгоду для предприятий [19]. Ч. Фомбран, Н. А. Гардберг и Дж. М.Сивер улучшают количественные методы измерения репутации и разрабатывают свой коэффициент репутации, который учитывает не только интересы инвесторов и финансовых учреждений, но и иных групп стейкхолдеров [9].

Исследование Д.Гонзалез показывает, что большинство трудностей в управлении репутацией вызвано проблемами с регистрацией торговых знаков и доменов, смены названия компании или ее продукта, негативными отзывами, ложной информацией, плохими новостями о компании, жалобами и скандалами. Чтобы поддерживать репутацию на высоком уровне, согласно выводам Гонзалез, необходимо управлять отзывами и новостной повесткой вокруг предприятия [12]. Этот вывод более детально 
исследуется в работе К.Ли, Т. Ванга, П. Ли и других, где они заключают, что новости о предприятии и общественное мнение могут влиять на действия инвесторов, при этом направленность этого влияния зависит от характеристик предприятия и содержания самой новости [26].

На репутацию предприятия, помимо новостей, влияет также активность пользователей в социальных сетях. Более того, высокотехнологичным компаниям необходимо отслеживать свои упоминания в социальных сетях, поскольку отрасль информационных технологий является одной из наиболее освещаемых на данных площадках, согласно исследованию Б. Каушика, Х.Хемани и П.В.Илаварасан [16]. Авторы данного исследования не смогли найти связь между обсуждениями компаний в социальных сетях и динамикой их акций, однако в более позднем исследовании Э. Тети, М. Даллоччио и А.Аниаси эта связь была обнаружена при помощи анализа активности пользователей Twitter [25]. Здесь также стоит упомянуть работу К.Жанга, Х.Фуереса и П.А.Глура, где они проанализировали сообщения в Twitter за последние 6 месяцев на наличие в них оптимизма или пессимизма по поводу динамики акций и индексов и пришли к выводу, что любые эмоциональные всплески в Twitter отрицательно коррелировали с динамикой индексов Dow Jones, NASDAQ и S\&P500, но положительно с VI, при этом авторы отмечали, что в собранных данных оказалось больше оптимизма о динамике индексов, чем пессимизма [31]. В похожем исследовании В.Вей, Ю.Мао и Б.Ванг пришли к выводу, что волатильность финансовых инструментов становится меньше после всплеска активности в Twitter, чем до него, а также попробовали сформировать портфель финансовых инструментов исходя из анализа активности обсуждений в Twitter, который в симуляции оказался в 3 раза выше по доходности, чем индекс S\&P500 [29].

Недавнее исследование Х. Максуда и других, основанное на анализе 11,24 миллионов собранных сообщений в Twitter, так же позволило заключить, что анализ тональности позволяет лучше прогнозировать фондовую динамику [2]. М. Сииканен и другие в своей работе исследовали данную проблему с другой стороны и изучили влияние информации из Facebook на действия различных групп инвесторов: информация из этой социальной сети очень сильно влияла на инвестиционную деятельность домашних хо- зяйств и некоммерческих организаций, в то время как финансовые организации зависели от этого гораздо меньше [8]. Ю.Сун и другие так же смотрели на действия инвесторов и пришли к выводу, что внимание со стороны средств массовой информации положительно влияет на действия инвесторов, а зависимость между вниманием СМИ и инвесторов и динамикой акций имеет параболическую форму с ветвями вниз [14]. Также примечательно, что в рамках данного исследования они нашли 2 кластера микроблогов.

Стоит отметить, что обсуждение информации в социальных сетях и появление новостей в иных средствах массовой информации по-разному влияют на динамику акций компаний. Согласно работе П.Джиао, А.Веига и А.Вальтера, освещение новостей в традиционных СМИ увеличивает волатильность на рынках, в то время как освещение этих же новостей в социальных сетях имеет обратный эффект. Это связано с тем, что пользователи часто распространяют новости в социальных сетях и обсуждают их, что приводит к эффекту «эхо-камеры» [15].

Для более детального понимания репутации и ее влияния на деятельность технологических компаний стоит определить субъекты, которые могут формировать или анализировать репутацию предприятия. Представленная на рисунке 3 схема отражает движение информационных потоков между компанией и ее клиентами на B2C-рынке. Видно, что ключевыми посредниками между предприятием и потребителями в формировании ее репутации являются традиционные СМИ и социальные сети. Потребители могут прямо влиять на информацию, распространяемую в социальных сетях, публикуя новый контент или делясь уже опубликованным, но не могут влиять на информацию о компании в традиционных СМИ, а лишь только ее потреблять. При этом между традиционными СМИ и социальными сетями может быть обмен информации - например, когда потребители делятся информацией о своем опыте взаимодействия с компанией и она вызывает интерес у общественности, либо наоборот, когда потребители обсуждают новости о действиях компании или иных событиях, связанных с ней, о которых узнали из традиционных СМИ.

Представленная на рисунке 4 схема обмена информационными потоками между предприятием и клиентами на В2B-рынке имеет ряд схо- 


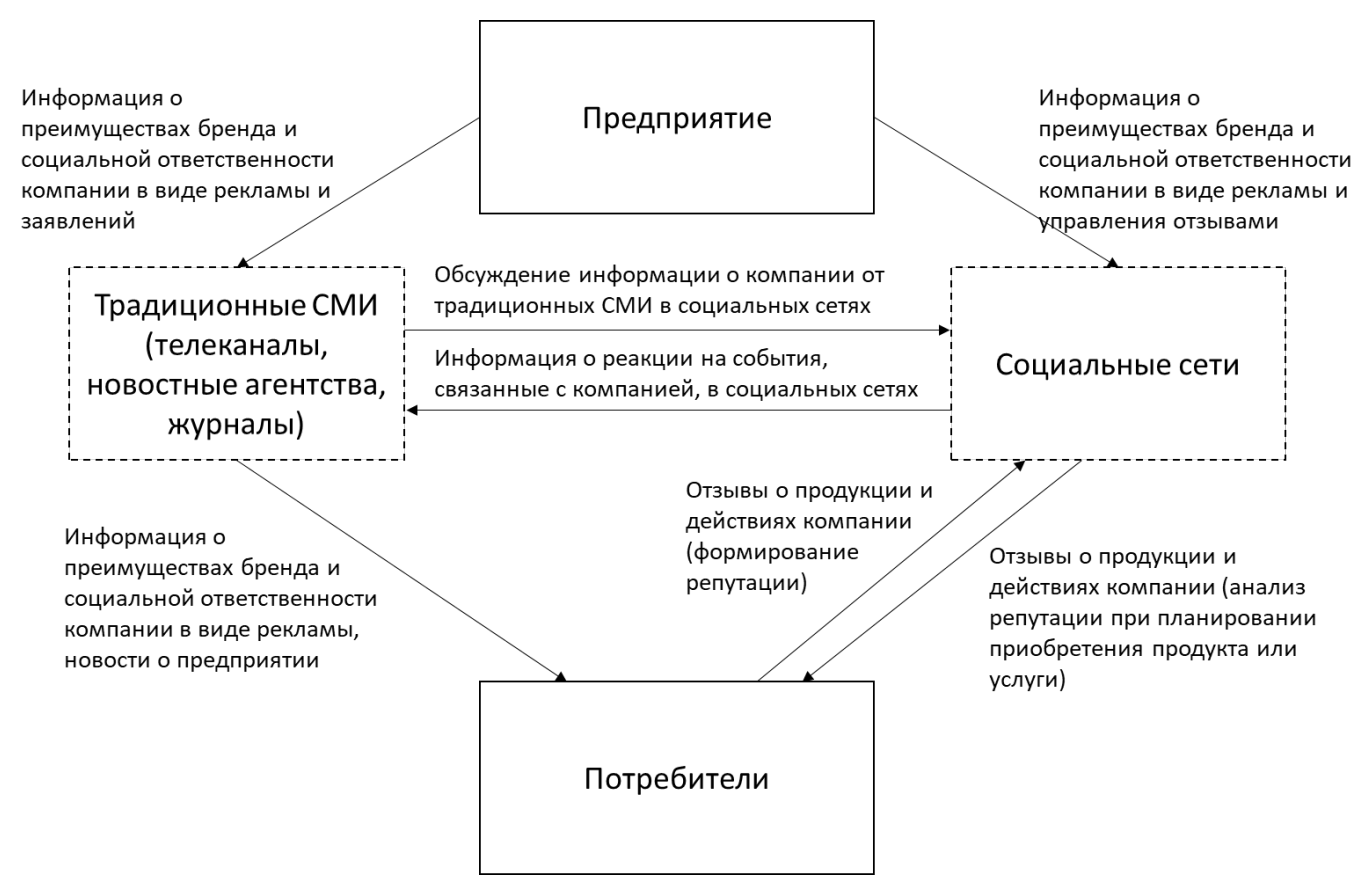

Pис. 3. Движение информационных потоков от предприятия к потребителям на В2С-рынке.

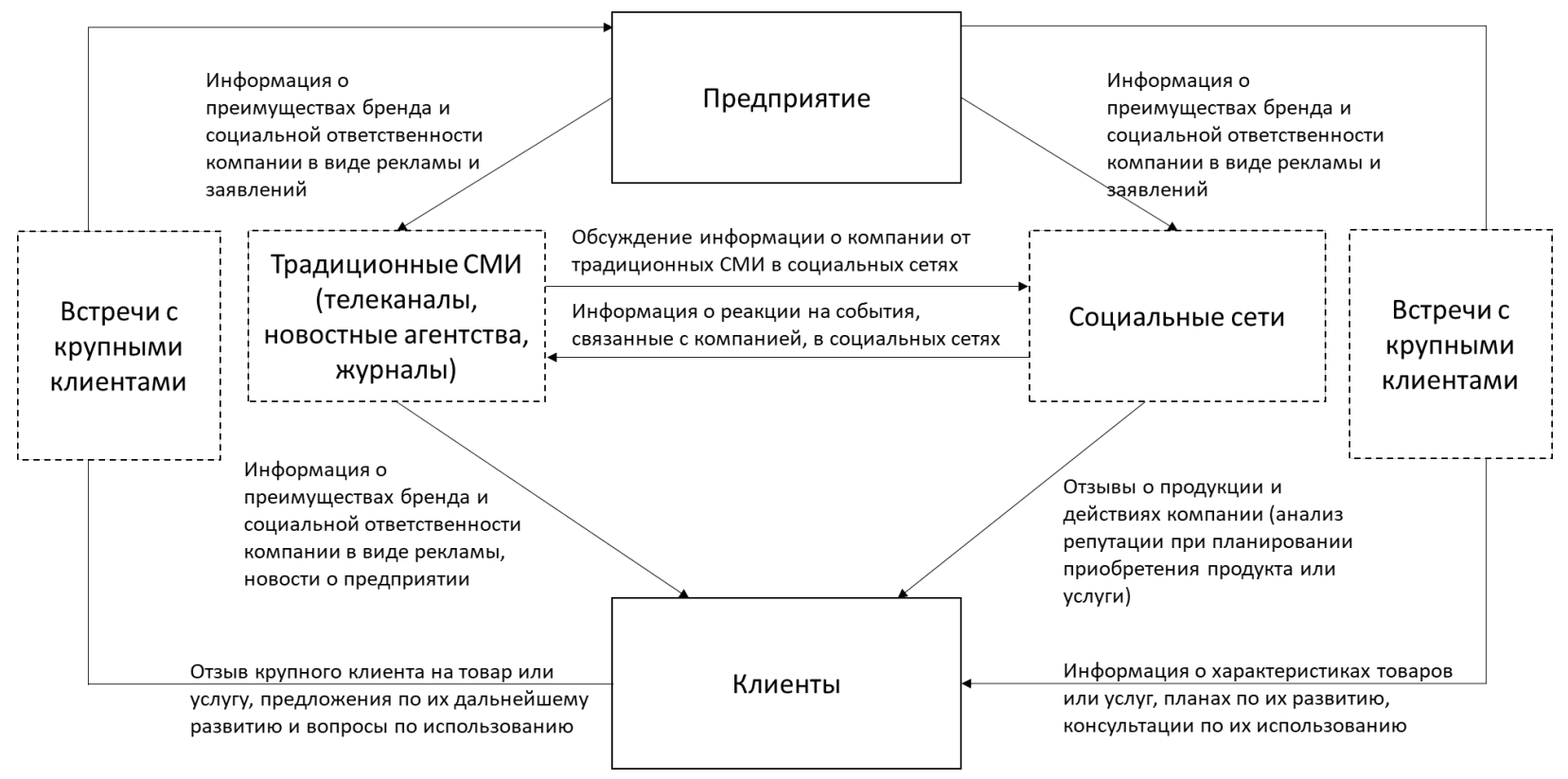

Рuc. 4. Обмен информационными потоками между предприятием и его клиентами на В2В-рынке.

жестей с предыдущей схемой - в данном случае тоже имеются посредники в виде традиционных СМИ и социальных сетей. Однако можно заметить, что предприятие на данном рынке может напрямую обращаться к крупным организациям, приобретающим их товары и услуги, избегая слабо контролируемого влияния посредников. Еще одно отличие состоит в том, что крупные клиенты в виде организаций не делятся отзывами об использовании продуктов предприятия в социальных сетях, однако могут анализировать в них информацию о самом предприятии.

Репутация важна не только для потребителей, но и для инвесторов компании. Рисунок 5 показывает, что модель обмена информацией между предприятием и инвесторами похожа на модели обмена информацией с клиентами. Акционеры и кредиторы, как и потребители, могут анализировать информацию о предприятии в социальных сетях, а также делиться своими 


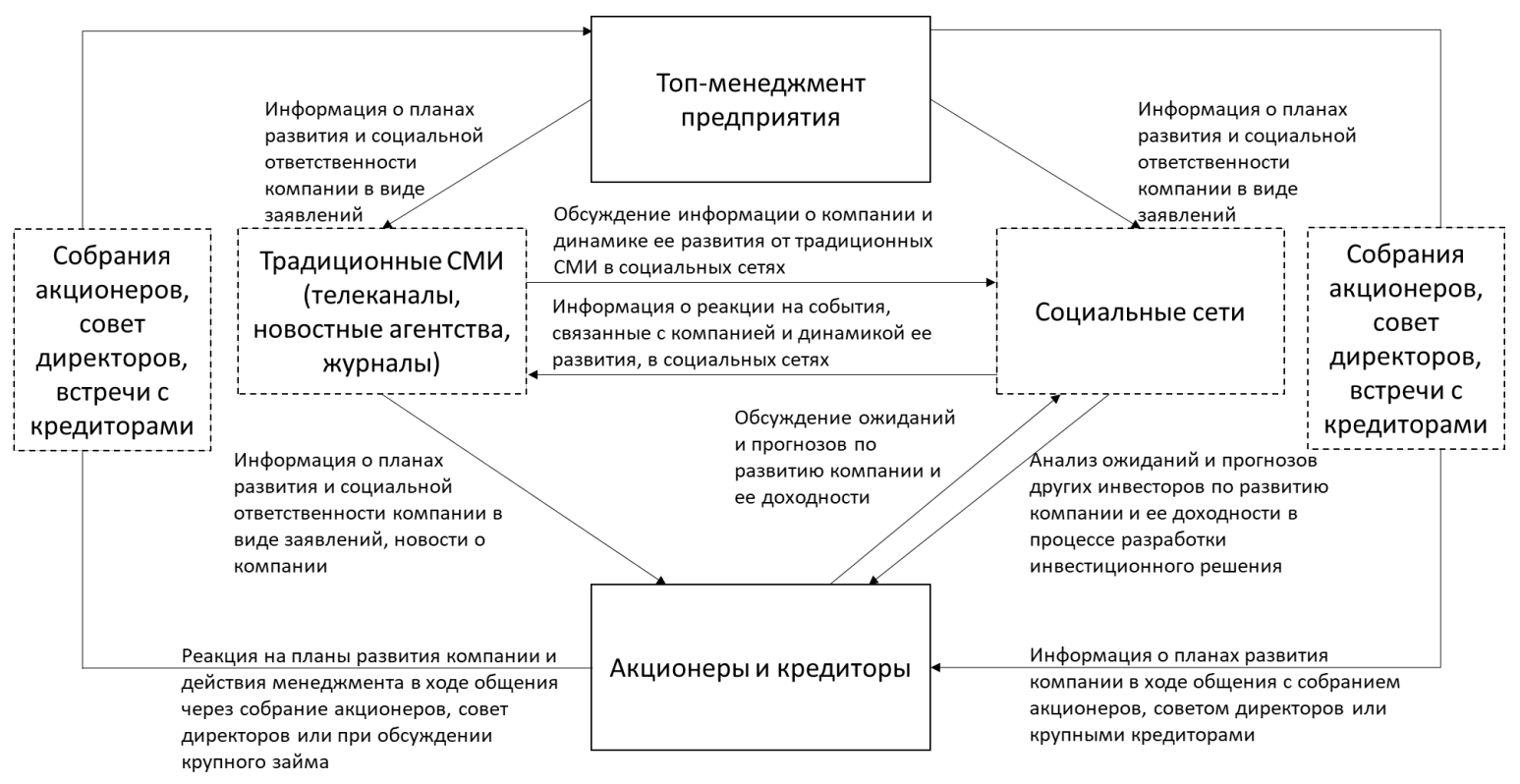

Puc. 5. Обмен информацией между предприятием и инвесторами.

ожиданиями о перспективах ее развития и доходности от вложений средств в данную компанию. Они так же потребляют информацию от традиционных СМИ, обмен информацией между традиционными СМИ и социальными сетями в данной модели тоже присутствует. При этом предприятие способно также оказывать прямое влияние на ожидания инвесторов, обмениваясь с ними информацией в ходе собраний акционеров, заседаний совета директоров или встреч с крупными кредиторами, таким образом избегая искажения информации в традиционных СМИ и социальных сетях. Таким образом, на капитализацию технологических компаний влияет множество факторов, в том числе:

1. Привлечение необходимых для компа- нии ресурсов;

2. Наличие внутренних компетенций компании по эффективному использованию этих ресурсов;

3. Управление репутацией среди различных групп стейкхолдеров.

Информационный обмен является одним из важнейших элементов управления экономическими показателями деятельности технологических компаний. Именно в ходе него формируется репутация компании среди клиентов, которым она предоставляет продукцию, и репутация компании среди инвесторов, которым она обещает доходность, рост акций или своевременность выполнения своих обязательств.

\section{Библиографический список}

1. Абдрахманова Г. И. Сектор ИКТ выработал иммунитет к COVID-перегрузкам / Г. И.Абдрахманова. // Национальный исследовательский университет «Высшая школа экономики»: [сайт]. - URL: https://issek.hse.ru/ news/446639217.html (Дата обращения: 02.12.2021).

2. A local and global event sentiment based efficient stock exchange forecasting using deep learning / H. Maqsood, I. Mehmood, M. Maqsood [и др.]. // International Journal of Information Management. — 2020. — № 50. - C. 432451.

3. Baden-Fuller, C. Business Models and Technological Innovation / C. Baden-Fuller, S. Haefliger. // Long Range Planning. - 2013. - № 46. - C. 419-426.

4. Cho, J. S. Corporate Social Responsibility and Corporate Financial Performance: Evidence from Korea / J.-S. Cho, Y.-M. Kwak, C. Choe. // Australian Journal of Management. - 2010. — № 35(3).

5. Companies ranked by Market Cap. // CompaniesMarketCap.com: [сайт]. - URL: https://companiesmarketcap. com/ (Дата обращения: 02.12.2021). 
6. Cravens, K. S. Employees: The key link to corporate reputation management / K. S. Cravens, E. G. Oliver. // Business Horizons. - 2006. - № 49(4). - C. 293-302.

7. Defining Strategic Quality Directions based on Organisational Context Identification; Case Study in a Software Company / M.L. Gaspar, S. G. Popescu, M.Dragomir, D. Unguras. // Procedia - Social and Behavioral Sciences. 2018. - № 238. - C. 615-623.

8. Facebook drives behavior of passive households in stock markets / M. Siikanen, К. Baltakys, J. Каnniainen [и др.]. // Finance Research Letters. - 2018. - № 27. - C. 208-213.

9. Fombrun, C. The Reputation QuotientSM: A Multi-stakeholder Measure of Corporate Reputation / C. Fombrun, N.A. Gardberg, J. M. Sever. // Journal of Brand Management. - 2013. - № 7(4). - C. 241-255.

10. FXIT | Цена ETF FinEx MSCI USA Information Technology UCITS ETF USD Share Class - Investing.com. // Investing.com - котировки и финансовые новости: [сайт]. - URL: https://ru.investing.com/etfs/finex-msciusa-info-tech-ucits-usd (Дата обращения: 02.12.2021).

11. Gatzert, $N$. The impact of corporate reputation and reputation damaging events on financial performance: Empirical evidence from the literature / N. Gatzert. // European Management Journal. - 2015. - № 33. - C. 485-499.

12. Gonzales, D. Managing Online Risk / D. Gonzales. - 1-е изд. -: Butterworth-Heinemann, 2014. - 271 c.

13. Hensen, A. H. R. Hierarchical business value of information technology: Toward a digital innovation value chain / A. H.R.Hensen, J. Q. Dong. // Information \& Management. - 2020. - № 57.

14. How mood affects the stock market: Empirical evidence from microblogs / Y.Sun, Х.Liu, G.Chen [и др.]. // Information \& Management. - 2020. - № 57.

15. Jiao, P. Social media, news media and the stock market / P. Jiao, A. Veiga, A. Walther.// Journal of Economic Behavior \& Organization. - 2020. - № 176. - C. 63-90.

16. Kaushik, B. Social media usage vs. stock prices: an analysis of Indian firms / B. Kaushik, H. Hemani, P. V. Ilavarasan. // Procedia Computer Science. - 2017. - № 122. - C. 323-330.

17. Mashiah, I. "Come and join us": How tech brands use source, message, and target audience strategies to attract employees / I. Mashiah. // Long Range Planning. - 2021. - № 32.

18. Mirhayadri, A. Facebook stock recovers all \$134B lost after Cambridge Analytica data scandal / A. Mirhayadri. // CBS News: [сайт]. - URL: https://www.cbsnews.com/news/facebook-stock-price-recovers-all-134-billion-lostin-after-cambridge-analytica-datascandal/ (Дата обращения: 02.12.2021).

19. Mishra, S. Does Corporate Social Responsibility Influence Firm Performance of Indian Companies? / S. Mishra, D. Suar. // Journal of Business Ethics. - 2010. - № 95(4). - C. 571-601.

20. Percentage of the ICT sector on GDP. // Eurostat: [сайт]. - URL: https://ec.europa.eu/eurostat/web/productsdatasets/-/tin00074 (Дата обращения: 02.12.2021).

21. Perez-Cornejo, C. How to manage corporate reputation? The effect of enterprise risk management systems and audit committees on corporate reputation / C. Perez-Cornejo, E. de Quevedo-Puente, J. B. Delgado-Garcia. // European Management Journal. - 2019. - № 37. - C. 505-515.

22. Petter, S. Information Systems Success: The Quest for the Independent Variables / S. Petter, W. DeLone, E. R. McLean. // Journal of Management Information Systems. - 2013. - № 29. - C. 7-62.

23. Reputation Definition \& Meaning. // Dictionary by Merriam-Webster: America's most-trusted online dictionary: [сайт]. - URL: https://www.merriam-webster.com/dictionary/reputation (Дата обращения: 03.12.2021).

24. Syed, T.A.Resolving paradoxes in IT success through IT ambidexterity: The moderating role of uncertain environments / T. A. Syed, C. Blome, T. Papadopoulos. // Information \& Management. - 2020. - № 57.

25. Teti, E. The relationship between twitter and stock prices. Evidence from the US technology industry / E. Teti, M. Dallochio, A. Aniasi. // Technological Forecasting and Social Change. - 2019. - № 149.

26. The effect of news and public mood on stock movements / Q. Li, T. Wang, P. Li [и др.]. // Information Sciences. 2014. - № 278. - C. 826-840.

27. Vartiak, L. IDENTIFICATION OF INTERNAL AND EXTERNAL FACTORS AFFECTING BUSINESS EXCELLENCE / L. Vartiak. // Conference: Company Diagnostics, Controlling and Logistics. - Zuberec, Slovakia:, 2016. - C. 315326.

28. Veh, A. Corporate reputation in management research: a review of the literature and assessment of the concept / A. Veh, M. Goebel, R. Vogel. // Business Research. - 2019. - № 12. - C. 315-353.

29. Wei, W. Twitter volume spikes and stock options pricing / W. Wei, Y. Mao, B. Wang.// Computer Communications. 2016. - № 73. - C. 271-281.

30. What drives business failure? Exploring the role of internal and external knowledge capabilities during the global financial crisis / M. G. Martinez, F.Zouaghi, T. G. Marco, C. Robinson. // Journal of Business Research. - 2019. № 98. - C. 441-449. 
31. Zhang, X. Predicting Stock Market Indicators Through Twitter “I hope it is not as bad as I fear” / X. Zhang, H. Fuehres, P.A. Gloort. // Procedia - Social and Behavioral Sciences. - 2011. - № 26. - C. 55-62.

32. Zhu, J. A comparative study of the effects of different factors on firm technological innovation performance in different high-tech industries / J. Zhu, Y.Wang, C. Wang. // Chinese Management Studies. - 2019. - № 13(1). C. 2-25. 